\title{
The Event Book System: a community-based natural resource monitoring system from Namibia
}

\author{
GREG STUART-HILL ${ }^{1,2, *}$, RICHARD DIGGLE ${ }^{1,3}$, \\ BEVAN MUNALI ${ }^{1,3}$, JO TAGG ${ }^{1,4}$ and DAVID WARD ${ }^{1,5}$ \\ ${ }^{1}$ Natural Resource Working Group, Namibian Association of Conservancy Support organizations; \\ ${ }^{2}$ World Wildlife Fund, LIFE Project, P.O. Box 9681, Windhoek, Namibia; ${ }^{3}$ Integrated Rural \\ Development \& Nature Conservation, P.O. Box 24050, Windhoek, Namibia; ${ }^{4}$ Ministry of Environ- \\ ment \& Tourism, P. Bag Box 13306, Windhoek, Namibia; ${ }^{5}$ Namibian Nature Foundation, P.O. Box \\ 245, Windhoek, Namibia; *Author for correspondence (e-mail: gregshill@bigpond.com.au)
}

Received 20 September 2004; accepted in revised form 25 October 2004

Key words: Community development, Locally-based monitoring, Namibia, Natural resource monitoring, Wildlife management

\begin{abstract}
Namibia's Community Based Natural Resource Management program is a joint venture between government, national non-governmental organisations and rural communities. A component of the program involves communities in monitoring various aspects of their conservancy, ranging from wildlife numbers, through economic returns, to patrolling records and infringements of the rules. A main feature of community monitoring is the Event Book System, which differs from conventional monitoring in that the community dictates what needs to be monitored, and scientists only facilitate the design process and conservancy members undertake all data analysis. The system has been adopted with good results by more than 30 communal conservancies in Namibia, covering almost seven million ha, and is now also being piloted in six national parks. Continued emphasis is needed on enhancing community interpretation and use of data for active adaptive management, particularly where conservancy leaders are transient due to the democratic nature of local organizations. Moreover, because the system is driven by local priorities, it does not cover all aspects of a comprehensive biodiversity monitoring programme. Where society deems other biodiversity values worth monitoring, conservancies must either be willingly persuaded to act on this, or external systems must be established to cater for these needs. If a community already has a monitoring system of its own, a win-win solution might be for the community to be sub-contracted to undertake these 'external modules' on behalf of national agencies.
\end{abstract}

\section{Introduction}

Namibian legislation passed in 1996 GRN 1996 provides for the establishment of Conservancies that confer certain rights to communities on communal land to benefit from wildlife Ashley and Barnes 1996. In return, communities are required to assume some responsibility for the sustainable management of natural resources, in particular wildlife.

Namibia's Community Based Natural Resource Management (CBNRM) program is a joint venture between government, NGOs and rural communities. By assisting communities to establish and manage conservancies, the program aims to improve management and the sustainable use of biodiversity in 
communal lands. Management of natural resources is complicated because it involves many variables (wildlife, livestock, rangelands, fire, rainfall, etc.) and depends on the objectives of the community: the same area could be used for cattle production, game farming, tourism, crop farming or a mixture of all of these. As a result of this complexity and an incomplete understanding of how the ecosystem functions, conservancies use an adaptive management approach Walters and Hilborn 1978. Central to adaptive management is a requirement for conservancies to set in place monitoring systems to check to see if the objectives are being reached Stuart-Hill 2003.

The monitoring systems started at the beginning of the CBNRM program were conventional in that external experts (scientists) working in government or NGOs designed them. Field staff (conservancy members) collected the data, data sheets were handed in and subjected to expert analysis. Many communities never received feedback due to the experts moving on, data being lost, computer problems, etc. In cases where the experts did return results, there were often lengthy delays and community members did not intuitively understand the resulting graphs, tables and maps Knott 2002. The consequence was no ownership of the monitoring process or results and conservancies struggled to maintain these systems beyond a few years.

Over the past three and half years, a simpler yet more effective monitoring system has been developed. This system is based on the principals of adaptive management Martin 2003 and aims to constantly review the monitoring results and if the objectives of the conservancy are not being achieved take required actions to address the situation. This system is known locally as the "Event Book System", and is designed around meeting the information needs of the local community. It gets its name from the challenge of monitoring events that occur stochastically e.g. fire, poaching, problem animal incidents, wildlife mortalities, etc. The system also makes provision for more systematic and planned monitoring activities (e.g. vegetation monitoring or wildlife censuses). A more correct term for this methodology might be a management orientated monitoring system.

The "Event Book System" differs from the conventional way of monitoring in that: (i) the community decides on what they want to monitors, (ii) the technicians only provide support upon request from the conservancy and facilitate the design process; and (iii) all data collection and analysis is undertaken locally by conservancy members.

To support local design, yet provide some national standardized and rigorous methodology, the monitoring system has over time been modularized by topic or theme. Topics/themes could for example be: problem animals, poaching, vegetation, predators, fish, etc. Once the conservancy has selected what it wants to monitor, the technical support team then provides a complete kit for each monitoring topic. Each kit contains 'tools' for: (i) data collection, (ii) monthly/quarterly reporting and (iii) reporting and analysing long-term trends. These three different levels of data collection and analysis have been colour coded to reduce confusion. 
Whilst the entire system is appropriately paper based (for remote area dwellers), it is nevertheless possible to analyse the data using digital technology thereby allowing for more sophisticated analysis. Each year data are copied during an annual review of each conservancy and are captured within a national monitoring and evaluation database. This database belongs to the Ministry of Environment and Tourism and is being used by the government and the Namibian Association of Conservancy Support Organizations for strategic decision making such as guiding quota setting, allocation of technical support, compliance monitoring, etc.

This paper reviews the development of the "Event Book System" since its inception in 2000. It covers how the system is organised, how data are recorded and stored, and provides examples of the kinds of results that can be derived from the information. Finally, it outlines how the system has been used to assist local communities to gain control over their own natural resources and the decisions that affect them, and presents a summary of the lessons learned by the team implementing this work.

\section{The Event Book System}

Within the Namibian Conservancies, two types of monitoring are recognised:

1. those that can be planned (e.g. game census, veld monitoring, patrols, etc); and

2. those that cannot as they are more stochastic (e.g. fire, poaching, problem animal incident, mortalities of wildlife, etc).

For the first type of monitoring conventional 'hand-in' data sheets (colourcoded yellow) are used to record data. These are managed and stored centrally. For the stochastic events another system has been developed, which has become known as the "Event Book System". The system also caters for more regular monitoring and for reporting to government, donors and other external stakeholders.

\section{Description}

The Event Book System operates within three levels of institutional hierarchy within a single conservancy, generally being: (i) community rangers (also called game guards or environmental shepherds) who report to (ii) a natural resource supervisor who in turn reports to (iii) a conservancy manager or an elected chairman.

The Event Book is a personalised A5 ring file maintained by each community ranger. The file contains a set of yellow cards, one card for each monitoring theme/topic - i.e. there is a card for poaching, a card for problem animal incidents, rainfall and so on. As events occur the ranger selects the appropriate card and records the event. At the end of the month a line is left and the same 
card used for subsequent events in the ensuing months. At the end of the year, all of the old cards are removed, archived and a fresh set of cards inserted into the book.

Data collection, analysis and reporting are done locally. It is considered essential that the people collecting the data should also analyse and interpret it, even if the analysis is sub-optimal. This principle emerged from failures with the conventional system (where data sheets are filled in and then handed over to an external technical expert to capture, analyse and report back). Lack of feedback or overcomplicated analysis resulted in a loss of ownership of the process and results and led to a decline in data collection efforts.

For each monitoring topic there is a complete system that begins with data collection, goes through monthly reporting and ends with long-term reporting (Figure 1). Colour coding is used to avoid confusion between these data-flow levels; with a) yellow for data collection; b) blue for reporting within one year (i.e. monthly/quarterly reporting); and c) red for tracking long-term trends.

In each conservancy the community decides on what they want to monitor (although there are some issues on which conservancies are obligated to report to government). Agreement on what to monitor is reached through a workshop involving community leaders and the community rangers. The workshop starts with a brainstorming exercise where all issues of importance are noted. The rest

\section{The 'Event Book' - a Community Ranger's Monitoring System}

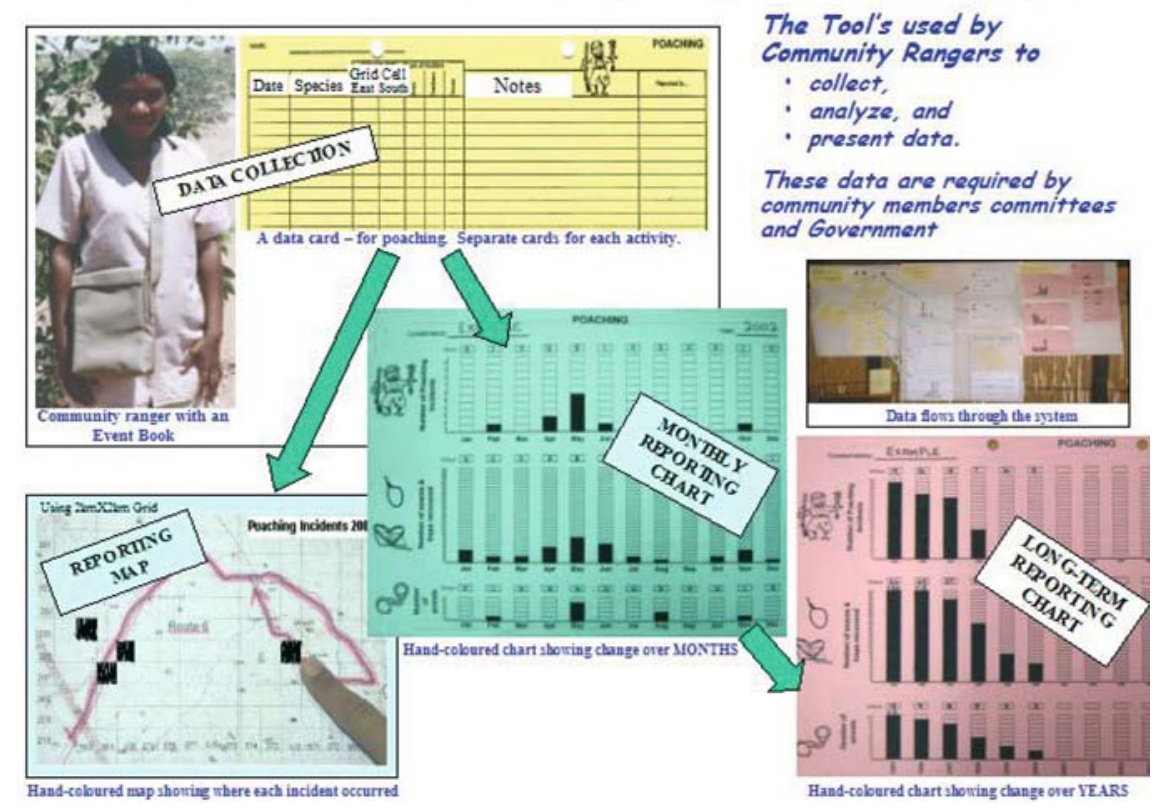

Figure 1. Example of some 'Event Book' data collection and reporting tools that community rangers use on communal rangelands in Namibia, using poaching as an example. 
of time is spent identifying what should be monitored - i.e. those that are central to livelihoods, key threats and indicators to track management plan targets. To make the selection of topics absolutely clear to all members of the community a 'job description poster' is constructed (Figure 2). This is essentially a mind map of a community ranger's monitoring work and contains

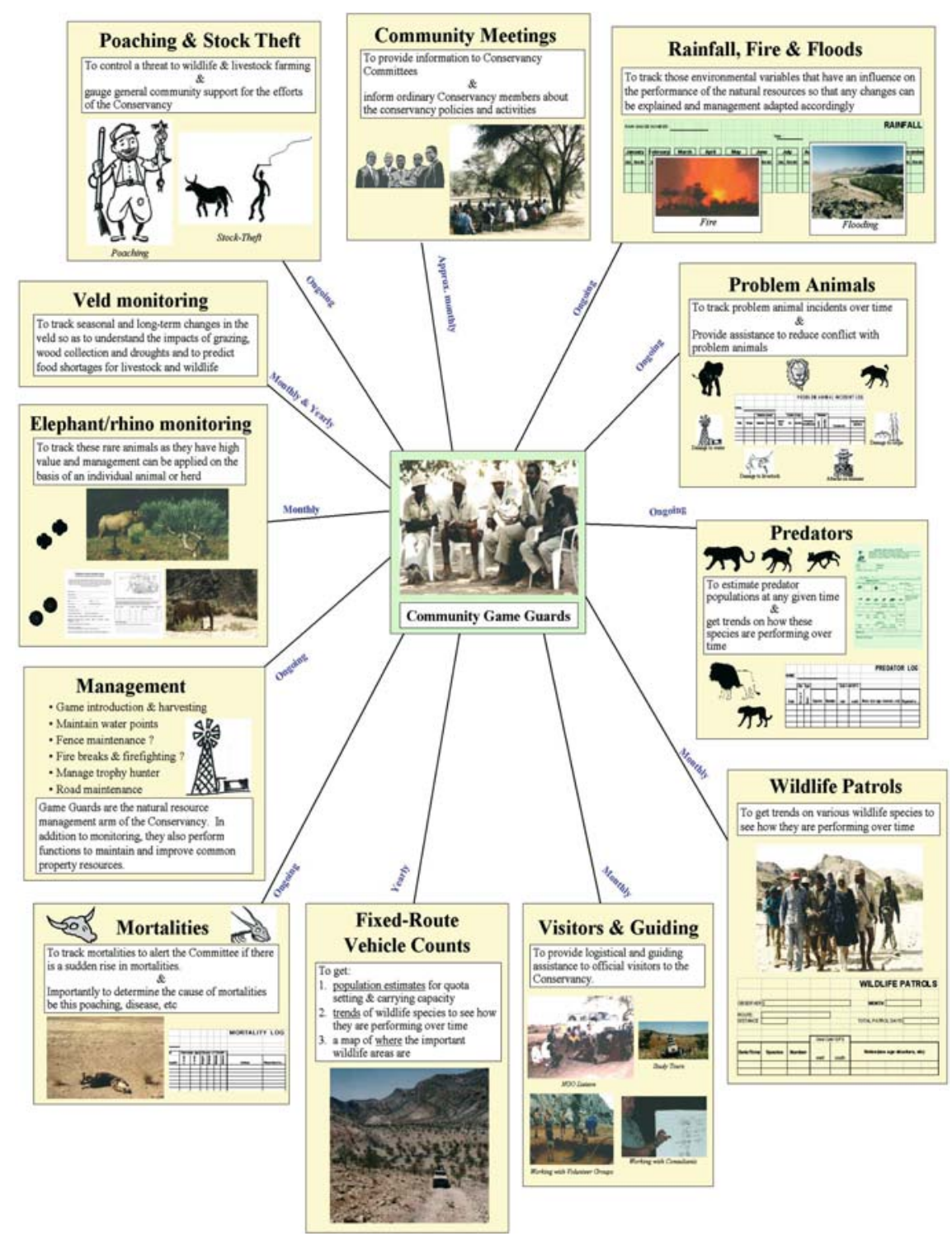

Figure 2. 'Job description poster' of a community game-guard in a typical Conservancy in the arid north-west communal lands of Namibia. 
pictures and icons to assist semi- and illiterate members of the community to understand and recall the tasks of the community rangers.

Twenty-one modules have been developed so far, as follows: Problem animal incidents; Poaching; Predator encounters; Rare and endangered animals; Fence monitoring; Water point monitoring; Flooding and river levels (for those conservancies that are in flood plains); Rainfall; Wildlife sighting during fixed foot patrols; Wildlife mortalities; Trophy hunting; Wildlife harvesting; Livestock mortality; Livestock theft; Livestock condition; Fishing effort; Fish catch trend; Long-term vegetation change; Seasonal grass grazing assessment; Craft resources; Wildlife re-introductions. New conservancies can share these materials and gradually build their monitoring program at a pace with which they are comfortable. Over time, as needs, skills and confidence increase, more and more topics can be added with the end result that the conservancy may eventually be covering a wide spectrum of topics.

The role of experts in this process is to provide advice on how to gather, process and report the information for each monitoring topic that the conservancy selects. If a module has already been developed with another conservancy then these materials are made available to the conservancy. This automatically provides the community with appropriate data collection, analysis and reporting tools for the topic. It is not compulsory that the community use the materials but because these materials are largely standardised across the country, it simplifies the job of the supporting organisation to provide these materials on a sustainable basis. This approach is a win-win solution whereby the community gets to monitor what they want, whilst the supporting technicians only have to work with standardised materials.

At the end of each calendar year there is an annual audit of the system. This may be attended by a government representative, donors or any other stakeholders that the conservancy wishes to invite. The audit is based on a yes/no activity questionnaire. If the answer to any activity is 'yes, it was done', then the summary results are recorded. The completed questionnaire constitutes the conservancy's annual natural resource report and this is copied and sent to government, neighbours, donors, etc. The annual audit takes place each year in January. It takes approximately $2 \mathrm{~h}$ to complete and this includes archiving all the previous year's data, updating the red long-term reporting charts and placing fresh unused cards in the Event Book for the new year. Thus far, all conservancies have been very open with the results and have been happy to share this information with people from a wide variety of organisations. Presently, the conservancies take great pride in their annual reports and there is an element of competition between them.

\section{Analysis}

Current data 'analysis' is simple. There are three types of reporting: (i) monthly incident reports; (ii) annual reporting maps; and (iii) long term 
incident reports (see Figure 1). On a monthly basis, the senior ranger gathers all the field rangers together and they collectively complete the monthly (blue) reporting charts. These charts are pre-prepared A3 templates that are housed in a large format display 'flip-file'. The reporting principle is that one 'block' on the chart refers to one 'event'. For example, to report on poaching, one block is coloured in for each poaching incident, two incidents $=$ two blocks and so on. In some instances one block may represent standard values, e.g. $5 \mathrm{~mm}$ of rainfall or 10 animals seen whilst on patrol. There are A3 reporting templates for all of the monitoring topics and to avoid confusion these are prepared on blue card (Figure 3).

More advanced conservancies also complete reporting maps. One map is used for each monitoring topic and lasts a year (Figure 3). Incidents are recorded by hand onto the map using symbols used to differentiate between different types of incidents; e.g. for problem animals there would be different symbols on the map for say elephant (Loxodonta africana), lion (Panthera leo) or hyena (Crocuta crocuta) incidents.

Finally, at the end of each year, the totals for the year are transferred onto the long-term trend (red) reporting charts. These are similar to the monthly reporting charts and use the same method of colouring in blocks to represent number of incidents or quantities (e.g. mm of rain, or animals seen; Figure 4). The essential difference between the 'blue' and 'red' cards is that the $x$-axis on the latter is years rather than months. Colour coding the different reporting timescales has proved to be important to avoid confusion by semi-literate community members.

The entire system is paper-based, which seems to be the appropriate technology for remote rural communities and avoids the sustainability problems of ever-changing computer technology. All papers are filed in a specialized filing box. This simple tool has proved indispensable as it formalizes the system in an environment where conservancies often have no office. The data are archived by the conservancy and any data extraction is done by copying - i.e. if someone, a researcher or government official, wants data or a report then the information is copied and only the copy can be taken away. Original raw data never leaves the community!

Copied data can be transferred from paper and into digital format for purposes of central storage and analysis, thereby allowing more sophisticated analysis by scientists. All data also have a spatial element so can be entered into digital GIS systems for further reporting and analysis at the national level. Data from this database, originating directly from communities, has been used to compile a national State of Conservancies Report (Mendelsohn, 2004). Whilst primarily designed and managed to meet local information needs, the system has already provided information that has been used by national and on one-occasion international (e.g. CITES) decision makers. 

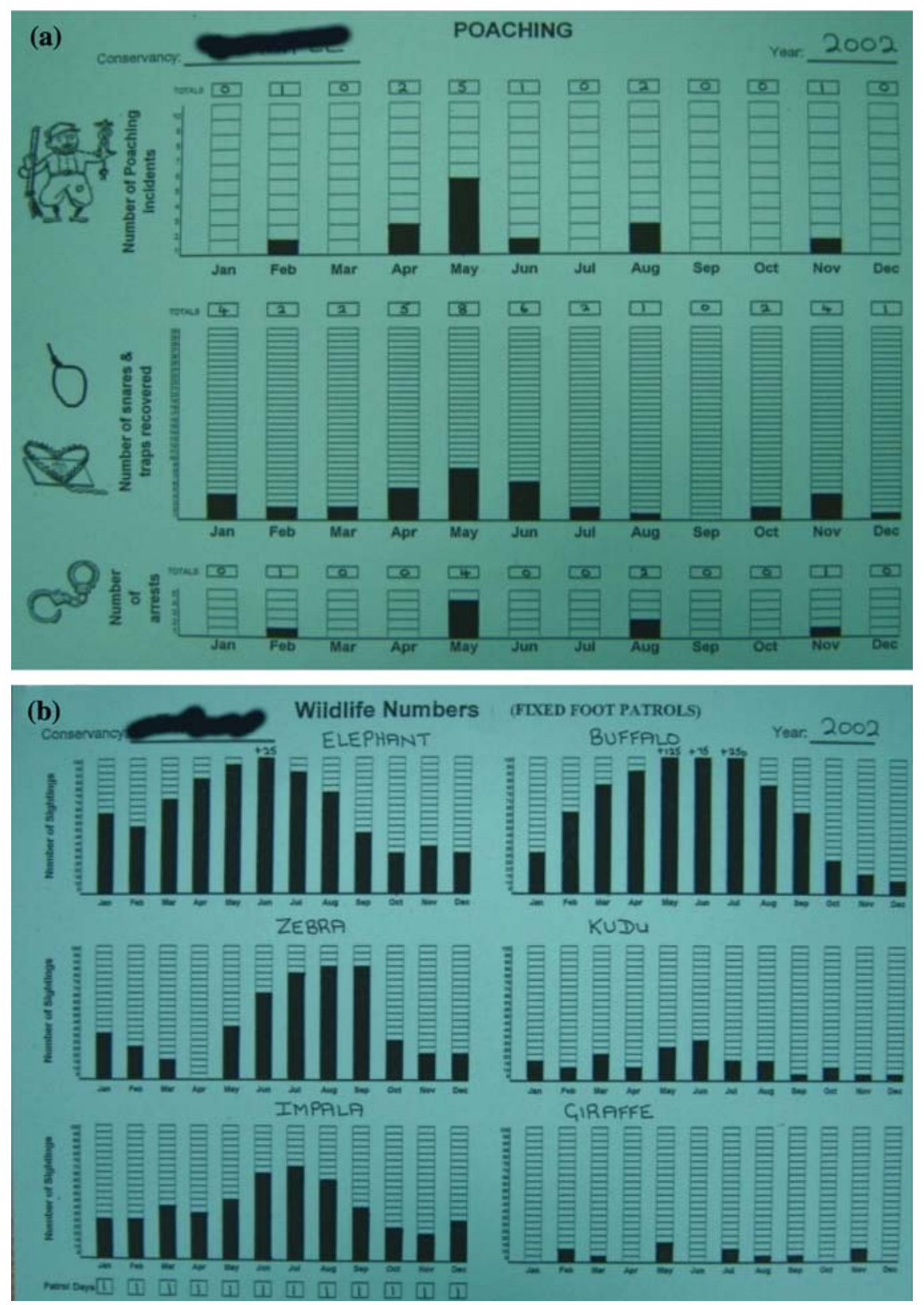

Figure 3. Photographs of original hand completed Namibian community reporting charts for (a) poaching and (b) wildlife numbers seen whilst community game-guards were on fixed-route foot patrols. The name of the Conservancy has been deleted. 


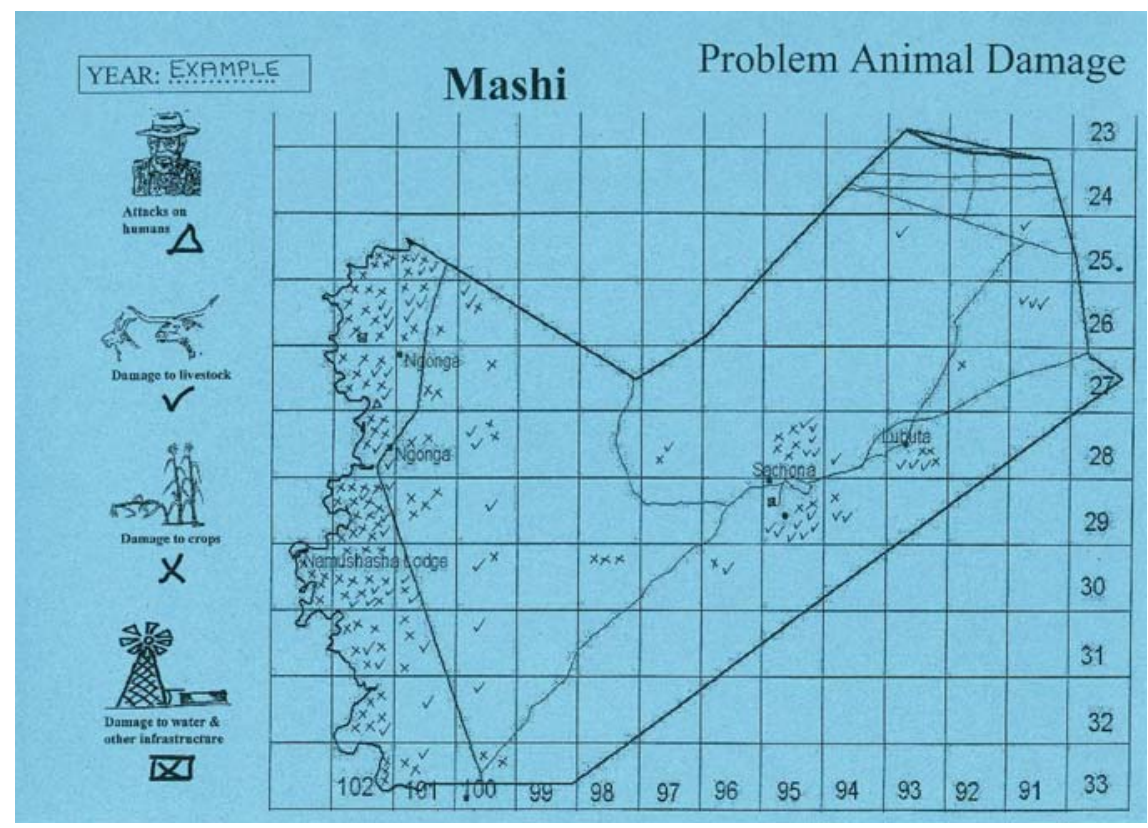

Figure 4. Example of a Namibian 'Event Book' reporting map.

\section{Implementation process}

Full implementation of the Event Book System takes a number of years. This is because it needs to be implemented incrementally, building on small successes, and the conservancy needs to go through at least 2 years of reporting to experience all aspects of the system. This presupposes that the participants have basic skills in map reading, filling in data forms and in general knowledge regarding the natural resources being monitored. Depending on the level of skill at a given conservancy, the average follow-up activities are every quarter during the first 12 months and every six months thereafter for at least 2 years. Each activity is kept short (max one day) so as to maintain interest.

The implementation phases are as follows:

1. Pre-event book phase-identification of persons who will be responsible for the system (institutional arrangements), basic skill training in resource management, map reading and data collection.

2. Job description phase (identification of resources to monitor)

3. Event Book training

4. Monthly report training

5. Annual audit

6. Institutionalization of the system

7. Interpretation and use of the information 


\section{Results}

The system began slowly in a few conservancies in late 2000. By the end of 2001 seven conservancies were successfully implementing the system. Presently, in excess of 30 communal conservancies in Namibia have adopted the system and are at different stages in its implementation (Table 1).

Data copied from conservancies during the annual review process in Namibia have been captured into a national monitoring and evaluation database. This database, belonging to the Ministry of Environment and Tourism, is being used by the government and the Namibian Association of Conservancy Support Organizations for national level adaptive management decision making. Examples of uses are: the allocation of quotas of high value species (elephant), the design of problem animal compensation schemes, compliance reporting of conservancies to government, and displaying community commitment to conservation to satisfy private sector and donor investment. The information also helps conservancy service providers to allocate technical and financial support to different communities. The database has also been used to contribute to a national State of Conservancies Report (Mendelsohn 2004) and has been used to support Namibia and Botswana's case for limited trade in ivory at the CITES meeting in 2002. Limited examples of the kinds of data and analyses that can be performed using the data obtained from the system are presented in Figures 7-9.

The success of the Event Book System in communal conservancies prompted the Ministry of Environment and Tourism to request that a similar system be piloted in six national parks in the north-east of Namibia. This system, known as the 'Incident Book' system is showing promising results which prompted the Director to express the desire to eventually see the system rolled out to all protected areas in Namibia. A similar system is also being piloted by Ministry of Environment and Tourism in one of their regional service areas (Nyae Nyae/ Gam), and is also being used in a private game reserve in southern Namibia (Gondwana Canyon Park).

The principles and approaches that evolved during the development of the Event Book were recognized during a donor review mission in 2002 (Child et al. 2001). This resulted in USAID providing funding for exchange visits for decision makers and community leaders in neighbouring countries to visit some of the Namibian sites. These visits have resulted in similar systems now being initiated for: (i) four protected areas in Mozambique (including marine resources); (ii) four community areas in Zambia; and most recently, (iii) three protected areas and two community areas in Botswana. These, with the exception of a community system adjacent to Kafue National Park in Zambia (which has made significant progress) are all still at the initial design and field testing stage and so have not yet started to produce results. 
Table 1. Progress chart for the implementation of the 'Event Book System' in communal conservancies in Namibia as at June 2004. This list represents approximately one half of the areas that could possibly emerge as communal conservancies in Namibia over the next 5 years.

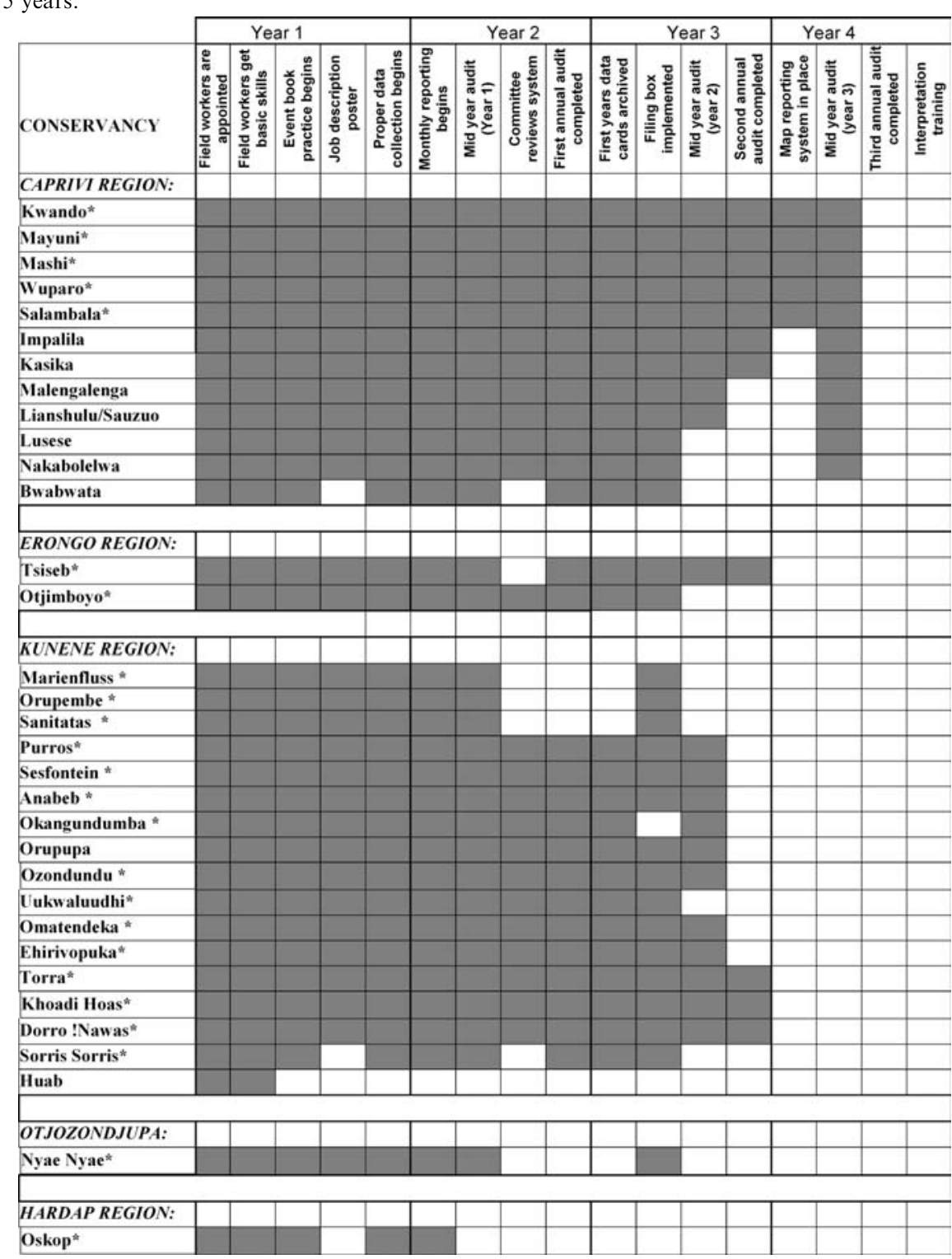

Note: * Registered Conservancies. 


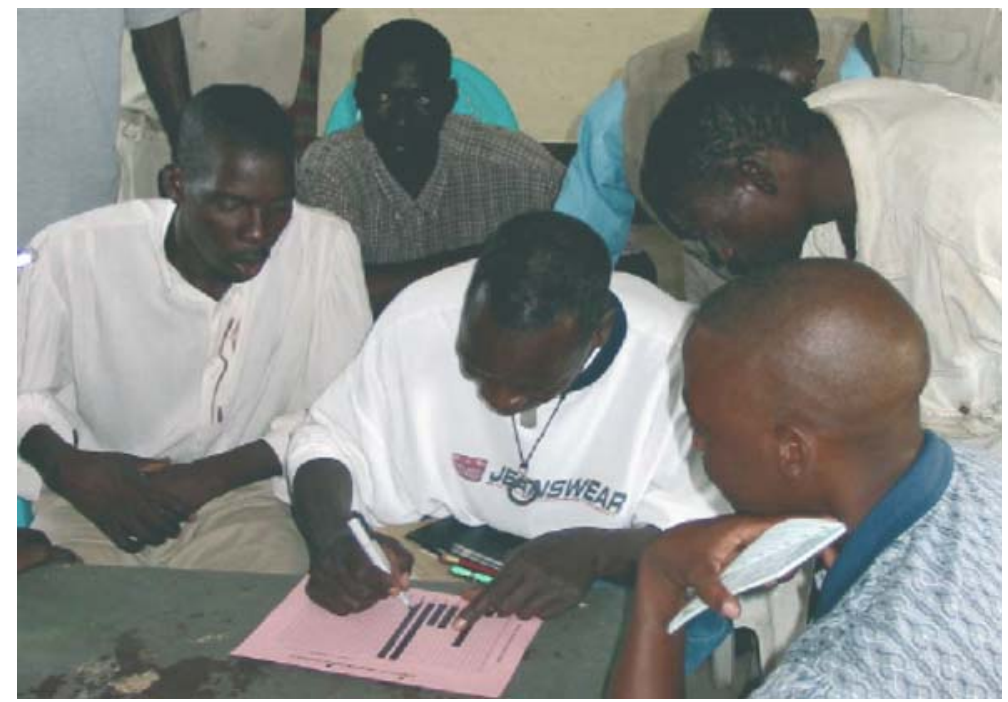

Figure 5. Committee chairman of a Namibian communal area conservancy completing long-term 'Event Book' trend charts ('Red Level').

\section{Discussion}

\section{Theoretical considerations}

The development of monitoring systems for land managers is an evolutionary process, involving the participation of all stakeholders. Critically important is to put the needs of the land managers first when designing these systems. The history of development of monitoring systems has been topdown with external experts telling managers what they need to manage and delivering data sheets for them to fill in with the promise that the experts will capture and analyse the data and prepare reports which will help managers in their decision making. Our experience in southern Africa is that the clients, be these National Park managers or rural communities, desperately want/need information but tend not to get what they want because the technical people (us) are too busy fiddling around with detail and trying to fine tune methods.

We suggest that there is a fundamental difference between a 'management orientated monitoring system' and a monitoring system for research purposes. 'Research-orientated monitoring systems' are designed to develop an understanding of ecosystem function and to meet publication rigour. Researchers may in good faith assume that the monitoring system that they have developed will be adopted by managers and used henceforth. Experience indicates otherwise. 


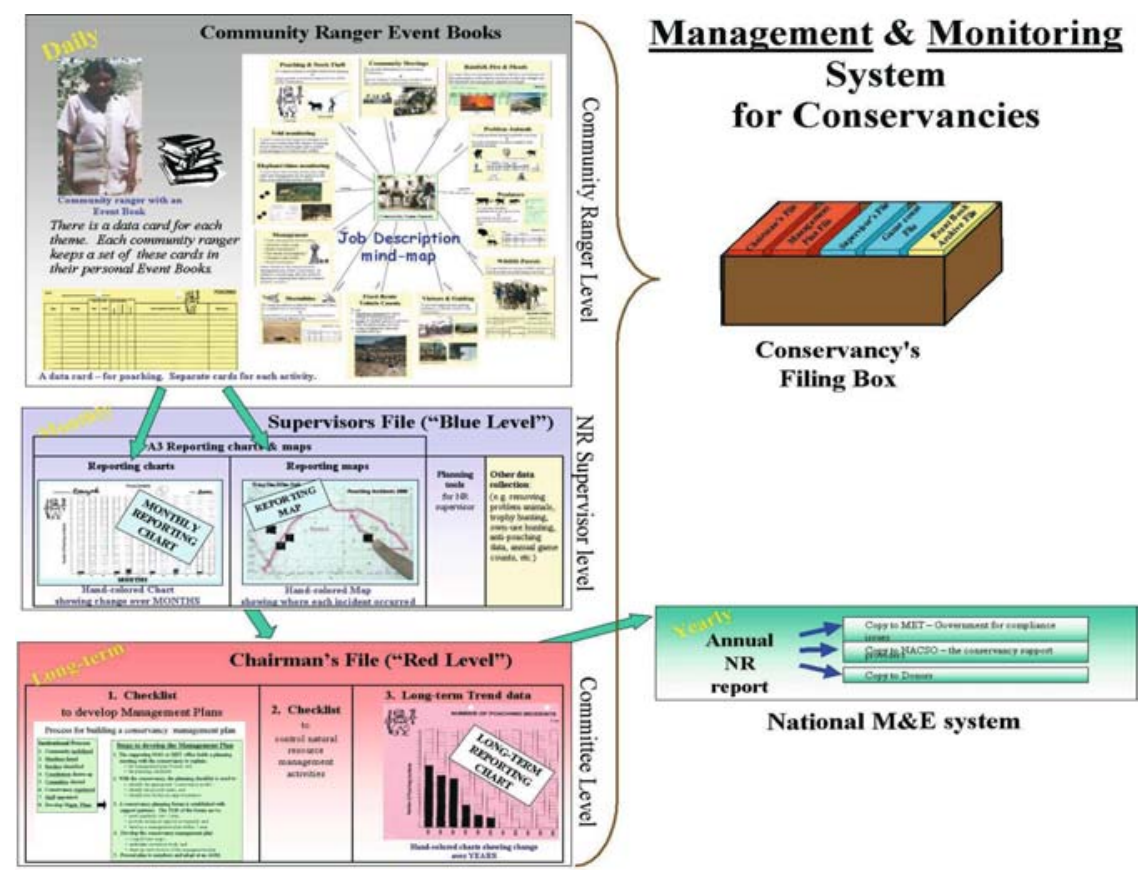

Figure 6. A training poster used to represent the entire Namibian 'Event Book' system. This illustrates the different levels of data collection and reporting, and the conservancy's filing box. The annual natural resource audit report provides data to the national conservancy monitoring and evaluation system.

The dichotomy between research- and management-orientated monitoring systems is best illustrated in protected areas. In these, the same agency is responsible for both management and monitoring. Many of these agencies employ scientists to run the management-oriented monitoring programs but problems arise when these scientists also have research and publications as their key performance areas. A management orientated monitoring system of necessity takes a long-term view and this timeframe is well beyond the publication frequency demanded of active researchers. Researchers, in an attempt to meet publication expectations, tend to continually refine the monitoring techniques with the result that the systems are modified frequently, become increasingly sophisticated and require more complex and time-consuming analysis. Over time, fewer and fewer people are able to manage the system, which leads to dependency on one or two individuals and inevitable nonsustainability when these people leave the organisation.

Land managers tend to want 'balanced' monitoring systems, i.e., a bit of information about a lot of things rather than lots of details about one or two components of the system. For example, scientists try to quantify biodiversity degradation in terms of changes in $\alpha$ and $\beta$ diversity. All the 


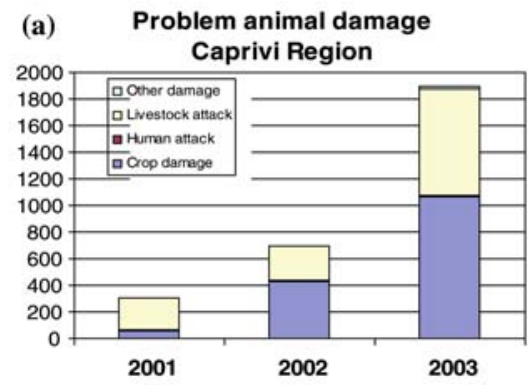

(b) Conservancy $\mathrm{X}$ - Number of poaching

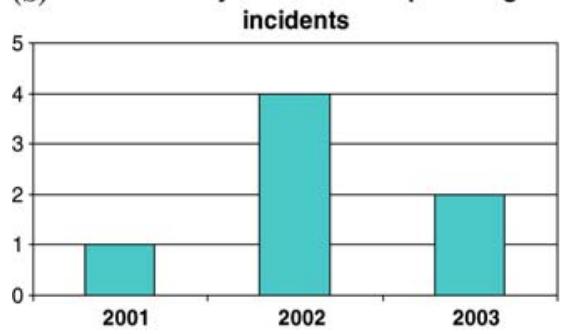

(c) Conservancy Y - Number of snares and

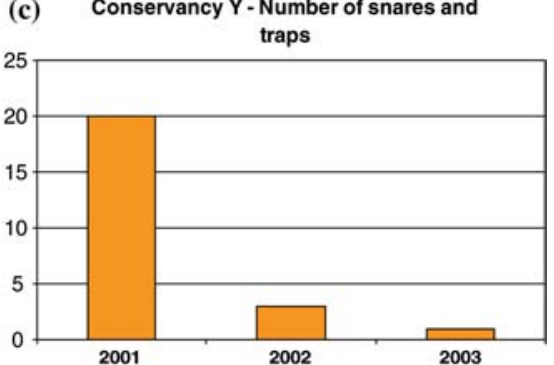

(d) Conservancy Z - Animals hunted for meat

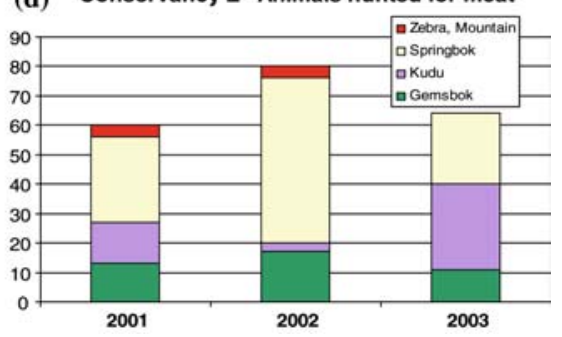

Figure 7. Examples of trend data (change over years) that have been collected by Namibian communities using the 'Event Book' System. These data were copied from conservancy records and show: (a) aggregated 'problem animal' damage incidents in conservancies in the Caprivi region; (b) number of poaching incidents; (c) number of snares and traps recovered; and (d) number of animals hunted for meat in individual conservancies. Names of conservancies have been removed.

typical manager wants answers to questions such as: are the key species declining, is the bush getting thicker, are elephants and fire reducing the amount of forest, are my resources being used effectively? Over time we have, in response to manager demand, widened the scope of the monitoring systems to include stock-theft, poaching, rainfall, fishing, thatch harvesting craft making and selling, tourist camp site management and more recently financial and asset management.

This argument does not suggest that there is no value in research monitoring. Rather that management orientated monitoring systems are different. In practice it is quite possible that two independent but related monitoring systems could be running in parallel in a given area: The primary one should be a management orientated monitoring system which will be management focused, institutionalized within the annual management cycle and designed to indicate success or failure towards the area's management objectives. The other monitoring initiative might be a research orientated monitoring system, which may, for example, be attempting to understand a particular dynamic, uncover reasons for failure or to test technical recommendations. Such programmes fall outside the annual management cycle. 


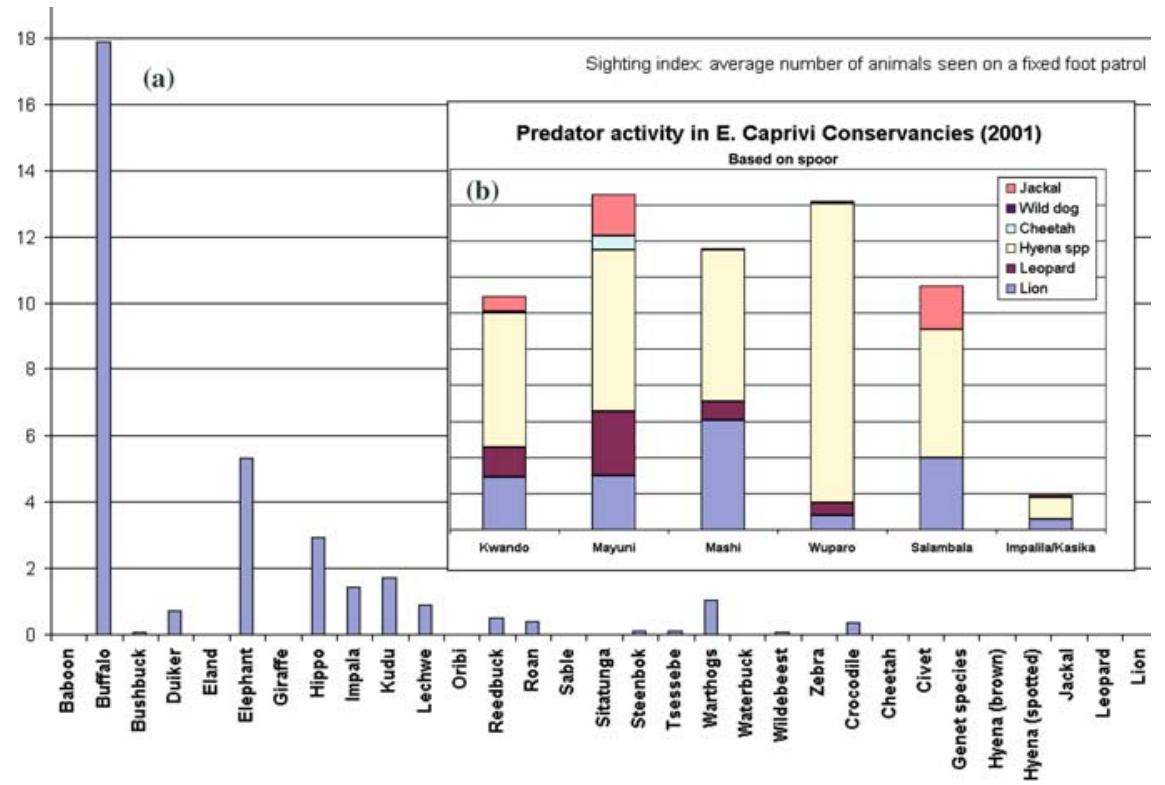

Figure 8. Examples of aggregated data collected by six communities in the east Caprivi Region of Namibia using the 'Event Book' System. These data were, with the permission of the managers, copied from conservancy records and show (a) the average number of animals, of different species, seen whilst on a fixed-route foot patrol; and (b-insert) large predator activity encountered based on spoor sightings.

\section{Level of analysis}

The simple self-analysis tools developed for information feedback in the Event Book System have been well received by both semi-literate community members and managers. Finding the means to systematically integrate monitoring results into the decision making process depends on circumstances. The Event Book System is increasingly enabling conservancy committees to view information and make their own decisions at their formalized quarterly planning meetings. The wider community is exposed to and uses the information for its own decision making at various village meetings and at the conservancy's annual general meeting. At the same time the annual reports compiled during the annual audit are used to facilitate compliance reporting that the conservancy is obligated to do to Government.

The annual reports from all the conservancies in Namibia are captured into a national database. This now forms a major component of the national CBNRM Monitoring and Evaluation system Weaver 2004. This information has influenced government, donor agencies and supporting NGO's decisions on providing technical support to different conservancies, has assisted in developing problem animal insurance (compensation schemes), setting regional wildlife harvest quota guidelines and in monitoring if the annual harvest of 

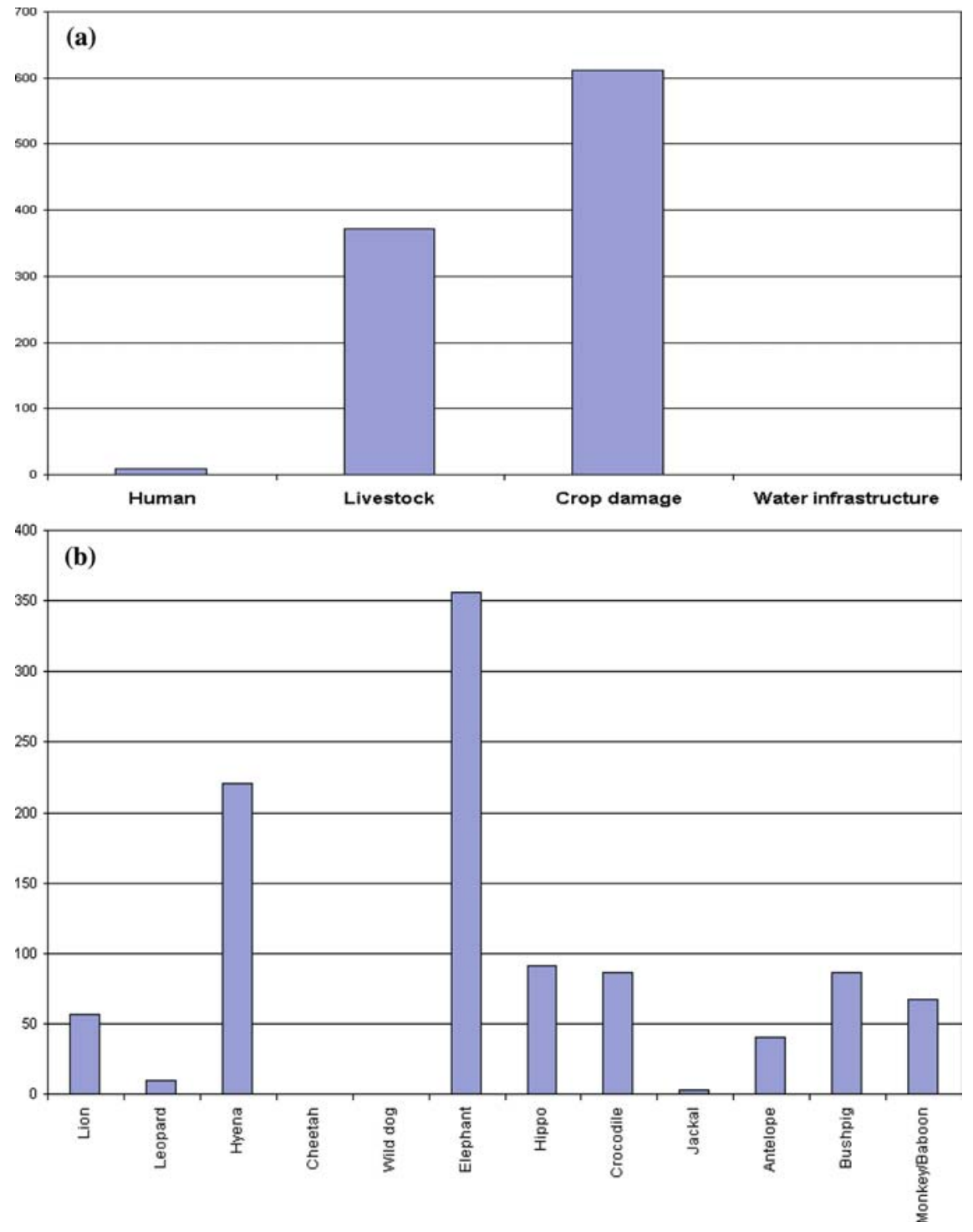

Figure 9. Examples of aggregated human-animal conflict data collected by communities in the east Caprivi Region of Namibia using the 'Event Book' System. These data were, with the permission of the managers, copied from conservancy records and captured into a national conservancy monitoring and evaluation database and show (a) the number of different types of conflict; and (b) the species involved in the conflict.

various wildlife species is within sustainable limits. An advantage of the Event Book system is that the management and monitoring efforts from many conservancies are being scaled up to form the basis of a national biodiversity monitoring and management initiative. 


\section{Problems encountered}

At the beginning of the process a number of technical problems were encountered. These were reviewed after one year of operation and a number of rules were developed. The rangers and their managers termed these the 'Ten Commandments' (Box 1). These rules have become the cornerstone for successful implementation of the Event Book.

Some other broader, non-technical, difficulties have also been encountered.

First, decision-makers in conservancies are elected representatives who change every few years. Whilst they are provided with the necessary information, many committee members have little knowledge about natural resource management (they may be teachers, nurses, police officers, etc.) and this means that there is also a need to provide training and technical support on the interpretation and use of the monitoring information.

Second, although establishing the system at a conservancy only requires limited technical support effort, it is critical that the effort is sustained over a period of at least 3 years. In Namibia we have been fortunate to have donors who have provided long term funding (in excess of 5 years). In addition we have built on the technical capacity and support relationships that local NGO's have built up with local communities over many years.

Third, successful establishment of the system ultimately depends on the management and motivation of the local participants. Despite being designed by the conservancy leaders, the Event Book is still implemented by individuals who if not managed can drift away from their key responsibilities. We have found that a critical aspect is careful allocation of job responsibilities. The "job description posters' make it clear to all concerned, which persons are responsible for what. This process has identified weak and strong community rangers, and managers, and has contributed to the institutional strengthening of a number of conservancies. An advantage of the Event Book system is because data are recorded and retained at an individual level (i.e. the data sheets are not passed on for analysis but rather copied) if the senior game guard disappears or

Box 1. The field rules devised for successful implementation of the Event Book. These were termed the 'Ten Commandments' by the community rangers

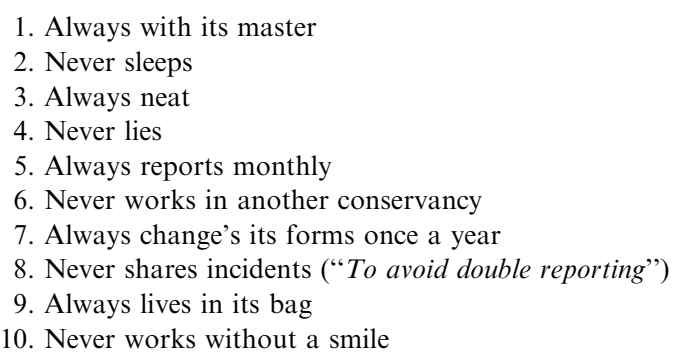


is incompetent, the system does not break down and can continue as long as necessary until a replacement is appointed.

Fourth, in some instances where individuals within a conservancy live large distances from one another, aggregating data into the monthly (blue reporting charts and maps) has proved to be problematic because it is difficult to bring all of the community game guards together on a monthly basis. In these instances, the blue charts can be compiled on a quarterly basis.

Fifth, individual conservancies do not have the necessary printing and photocopying equipment to generate and distribute the basic monitoring materials (event books, reporting charts, etc) on an annual basis. At present, it seems inevitable that there will be an ongoing requirement for a national support body. This does however represent an advantage as by standardizing materials (within each module) and printing large volumes of materials generates economies of scale. We suggest that this is a small cost against the benefit of aggregating local level monitoring data into the national database.

Sixth, some conservancies do not have sufficient resources to employ staff to undertake the day-to-day monitoring. In these instances individual farmers have volunteered to maintain event books and the data is aggregated for communal decision making as appropriate.

Seventh, a lack of literacy has presented some challenges in some conservancies. In these instances peer support from more literate colleagues or family members at the end of each day have enabled illiterate game guards to maintain their event books. Because the analysis and reporting is based on simply adding up incidents and colouring in blocks, illiterate members have been able to fully participate in the process. Over a number of months the literacy skills of community rangers often improves to the extent that they can complete the data cards unaided. However, extensive use is made of icons on the data cards, reporting charts and job description posters to assist illiterate people.

Eighth, in some instances individuals invented data to show that they had been working. This was quickly exposed during the collective reporting periods and interestingly, this was found to be most prevalent in areas where few incidents occurred. The issue of 'no data' being valuable information was specifically addressed. The technical support persons also intentionally displayed a nonchalant attitude emphasizing that the data belonged to the community. Presently, this seems to be a minor problem.

\section{Funding required}

How much of a conservancy's budget should be spent on monitoring remains a quandary. Ideally, monitoring budgets could be based on the value on having (or not having) the information and this relates to the cost effectiveness of monitoring systems (e.g. Hockley et al. 2005 (this issue)). Estimating the cost of monitoring is not really a problem, but quantifying the benefits is a significant challenge. In the interim, either a percentage of the value of the resource being 
monitored or a percentage of the value of the annual sustainable harvest could be used to motivate for long-term annual monitoring budgets. At present, many conservancies are carrying the cost of the Event Book out of own resources. Whilst the cost effectiveness of the system has not been analysed (but see Table 1 in Danielsen et al. 2005 (this issue)), it does not seem to have placed a significant additional burden on existing conservancy staff members.

\section{Lessons learned}

Lessons that have emerged during this process have led to the following suggestions for technical support providers. We believe that these apply equally to the development of community monitoring systems as those for protected areas.

1. Clearly separate research from monitoring. Remove research from the terms of reference of scientists responsible for facilitating the development of management orientated monitoring system.

2. Make a conscious effort to understand the working environment of a resource manager so as to realistically assess the level of commitment that management can devote to monitoring. Managers have to deal with many divergent issues,- e.g. meetings, budgets, audits, conflict management, public relations, human resources, stock control, litigation, political issues, etc. Many decisions need to be made urgently and, the average manager has little time to devote to the accumulation of information for the decision.

3. Focus on those topics that are dear to management. As trust develops the scope can gradually be expanded to include other issues e.g. those that help managers to identify effective and ineffective actions and/or longer-term trends in biodiversity.

4. Develop a service ethic where the managers are the primary 'clients' - i.e. do what they want, not what 'you' want. This includes listening carefully to what is required/wanted, following up on commitments, sometimes doing things simply to build relationships, learning to lose small battles in order to 'win the war'.

5. Purge all documents of scientific jargon.

6. Build on small successes rather than be too ambitious and end up with a large failure.

7. Be patient and pay attention to building sustainable monitoring systems rather than obtaining data at all costs.

\section{Acknowledgements}

This publication was made possible through support provided by the World Wildlife Fund for Nature (WWF, Namibia) Living in a Finite Environment (LIFE) Programme through funding from the United States Agency for 
International Development (USAID) Namibia Mission under the terms of the Cooperative agreement No. 690-A-00-99-00227-00. The views expressed in this document are the views of the authors and are not necessarily those of the USAID. This paper was prepared at the invitation of the Nordic Agency for Development and Ecology (NORDECO, Denmark), and the Zoology Department of Cambridge University (UK) as a follow-up to a symposium on locally-based monitoring held in Denmark in April 2004 (www.monitoringmatters.org). We acknowledge the hundreds of community game guards, resource monitors, conservancy committee members, conservancy managers and community members who have contributed to the development of the Event Book System through their enthusiastic participation and many hours of hard field work. The support of the consortium of conservancy support NGO's working under the umbrella of NACSO (Namibian Association of Conservancy Support Organizations) has been invaluable. So too has the guidance and support from officials in the Namibian Ministry of Environment and Tourism, and the Namibian Ministry of Fisheries for this work. We have greatly appreciated the opportunity to work together and distil lessons we have learned from our diverse experiences of monitoring. Finally we acknowledge the generous support from USAID and WWF who have provided ongoing funding for the development of the system. The stimulus to write this paper has come from many colleagues, in particular: C. Brown, C. Weaver, B. Child, R. Taylor, M. Nanchengwa and M. Funder. We also acknowledge the contributions of M. Funder, F. Danielsen and N. Burgess for their inputs into improving this manuscript.

\section{References}

Ashley C. and Barnes J. 1996. Wildlife use for economic gain. The potential for wildlife to contribute to development in Namibia. DEA Research Discussion Paper No 12. Ministry of Environment and Tourism, Windhoek, Namibia.

Child B., Page K., Taylor G., Winterbottom B., Awarab K., Bartel P. and Grimem C. 2001. MidTerm Review of LIFE-II and Assessment of the Namibian National CBNRM Programme. USAID, Windhoek, Namibia.

Danielsen F., Burgess N. and Balmford A. 2005. Monitoring matters: examining the potential of locally-based approaches. Biodivers. Conserv. 14: 2507-2542.

GRN 1996. Nature Conservation Amendment Act of 1996. Government Gazett No 1333, Republic of Namibia, Windhoek, Namibia.

Hockley N.J., Jones J.P.G., Andriahajaina F.B., Manica A., Ranambitsoa E.H. and Randriamboahary J.A. 2005. When should communities and conservationists monitor exploited resources? Biodivers. Conserv. 14: 2795-2806.

Knott K. 2002. Baseline Surveys for Identifying Biodiversity Indicators in Two Conservancies in Namibia Consultancy report. LIFE-WWF Programme, Windhoek, Namibia.

Martin R.B. 2003. Conditions for effective, stable and equitable conservation at the national level. In: Whande (eds), 2003 Local Communities, Equity and Conservation in Southern Africa. IUCN/CEESP Publications.

Mendelsohn J. (ed) 2004. Namibia's Communal Conservancies: A Review of Progress and Challenges. NACSO, Windhoek, Namibia. 
Stuart-Hill G.C. 2003. Keynote best practice paper 2: Natural resource management. In: Proceedings of the Regional Conference on CBRNM in Southern Africa: Sharing Best Practices for the Future. Windhoek, March 3-7.Namibian Association of CBRNM Support Organisations (NACSO, Windhoek, Namibia.

Walters C.J. and Hilborn T. 1978. Ecological optimization and adaptive management. Annual Review of Ecological Systems 9: 157-188.

Weaver C. 2004. End of Project Report - Phase II: Living in a Finite Environment (LIFE). Number: 690-A-00-99-00227-00.USAID, Windhoek, Namibia. 